\title{
COVID-19: Advances in diagnostic tools, treatment strategies, and vaccine development
}

\author{
M Sreepadmanabh, Amit Kumar Sahu and Ajt Chande* @ \\ Molecular Virology Laboratory, Indian Institute of Science Education and Research, Bhopal, India \\ *Corresponding author (Email, ajitg@iiserb.ac.in)
}

MS received 26 June 2020; accepted 15 October 2020; published online 24 November 2020

\begin{abstract}
An unprecedented worldwide spread of the SARS-CoV-2 has imposed severe challenges on healthcare facilities and medical infrastructure. The global research community faces urgent calls for the development of rapid diagnostic tools, effective treatment protocols, and most importantly, vaccines against the pathogen. Pooling together expertise across broad domains to innovate effective solutions is the need of the hour. With these requirements in mind, in this review, we provide detailed critical accounts on the leading efforts at developing diagnostics tools, therapeutic agents, and vaccine candidates. Importantly, we furnish the reader with a multidisciplinary perspective on how conventional methods like serology and RT-PCR, as well as cutting-edge technologies like CRISPR/Cas and artificial intelligence/machine learning, are being employed to inform and guide such investigations. We expect this narrative to serve a broad audience of both active and aspiring researchers in the field of biomedical sciences and engineering and help inspire radical new approaches towards effective detection, treatment, and prevention of this global pandemic.
\end{abstract}

Keywords. Artificial intelligence; CRISPR/Cas; SARS-CoV-2; treatment strategies; viral diagnostics

\section{Introduction}

The ongoing COVID-19 pandemic has had devastating effects on populations, social structures, and economic growth. These are further exacerbated by the increasing extent of global connectivity and geographical mobility, which expedite infection spread at an uncontrollable pace. The causative agent of this outbreak has been identified as the recently discovered SARS-CoV-2 coronavirus. Effective control and containment of this pathogen require reliable diagnostic assays and potent therapeutic agents. Recent advances in computational technology and biomedical engineering have placed a toolkit of immense potential in our hands, with a formerly unimaginable capability to enable multidisciplinary innovations and highly accelerated discoveries. In this review, we provide a critical evaluation of diagnostic techniques and treat-

This article is part of the Topical Collection: COVID-19: Disease Biology \& Intervention. ment strategies targeted at the SARS-CoV-2. Alongside an eclectic selection of such reports, our analysis also focuses on the applications, advantages, and pitfalls of emerging technologies like CRISPR/Cas, immune-informatics, artificial intelligence, and machine learning.

\section{Diagnostic tools for detecting SARS-CoV-2}

Figure 1 provides a graphical summary of the various approaches discussed herein.

\section{$2.1 \quad R T-P C R$}

PCR-based methods are considered the gold standard for viral detection. SARS-CoV-2 requires RT-PCRbased approaches, by virtue of being an RNA virus. In this section, we highlight some interesting developments as well as possible pitfalls of this technique, in the context of viral diagnosis. 


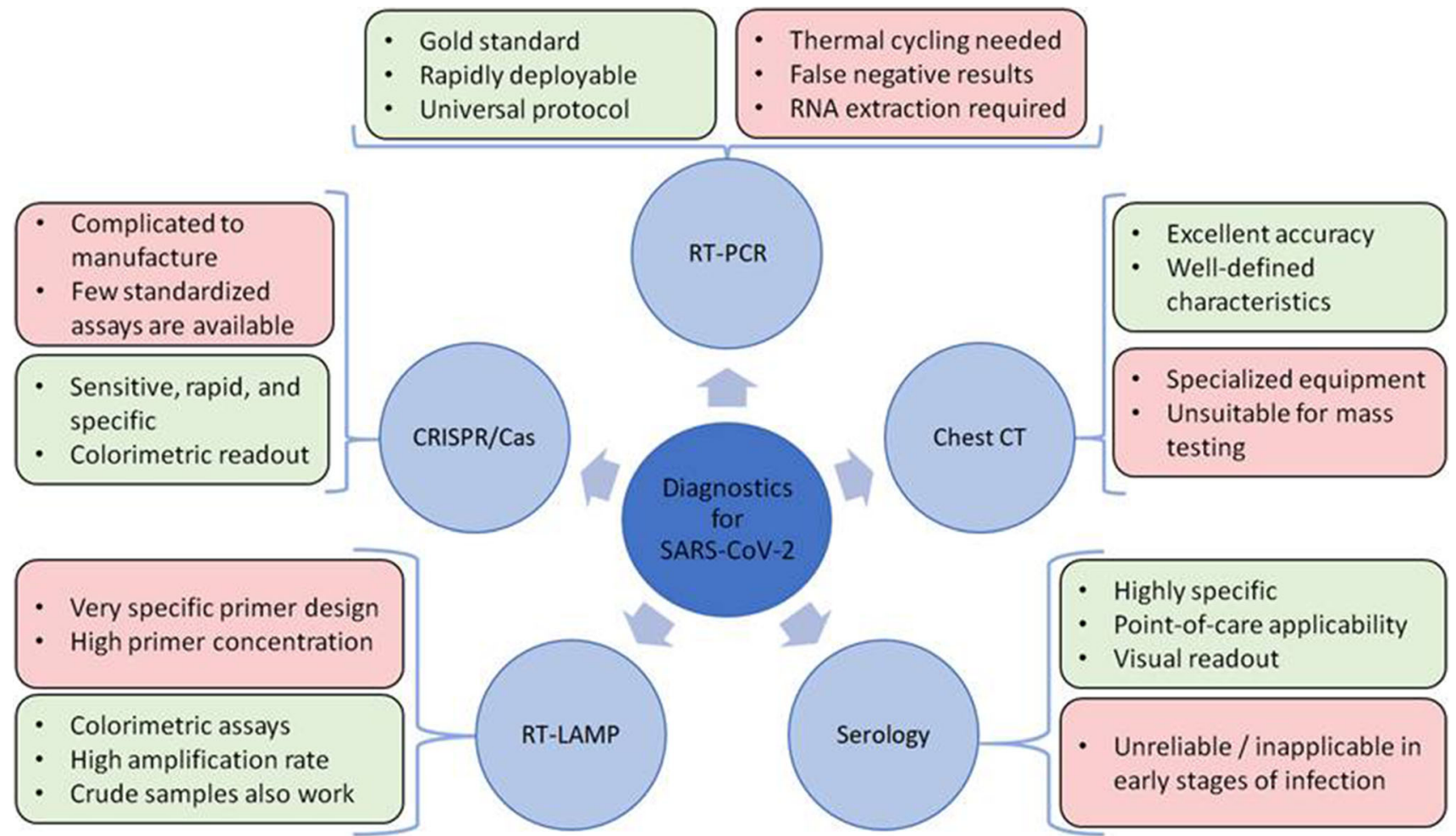

Figure 1. Summary of the various approaches towards diagnosis of SARS CoV-2 infection.

One of the earliest workflows set up in response to the outbreak was by Christian Dorsten and colleagues (Corman et al. 2020). The team established an accurate, sensitive, and specific RT-PCR protocol against the SARS-CoV-2. Later research, including a comparative study by Nalla et al., have attested to its superior sensitivity (Nalla et al. 2020). A notable feature of this pioneering work was that the assays were designed without access to any actual SARS-CoV-2 genomic specimens or patient samples, by relying on genome information sourced from Chinese researchers and synthetic nucleic acid technology. An interesting comparison between two commercially available testing kits - (the TaqMan ${ }^{\mathrm{TM}}$ 2019-nCoV Assay Kit v1 (ThermoFisher) and the 2019-nCoV CDC qPCR Probe Assay (Integrated DNA Technologies)) - was recently reported, results from which indicate that the former is capable of reliably detecting SARS-CoV-2 presence in nasopharyngeal swab samples without any RNA extraction steps (Beltrán-Pavez et al. 2020). Most diagnostic devices relying on RT-PCR-based amplification suffer from the drawback of requiring either sample lysis or purified nucleic acid samples, a step that involves additional reagents, increased testing time, human errors and costs, in addition to significant compromises on the field-applicability of the test. Subject to further validation, the above result represents a potential breakthrough for rapid and accessible diagnosis in low-resource settings, by enabling the development of accessible point-of-care devices. Additionally, while nasopharyngeal/oropharyngeal swabs are recommended sample collection techniques for SARS-CoV-2 testing, these pose a high risk of exposing healthcare workers to large numbers of potentially infected individuals, in addition to causing patient discomfort. An alternative in the form of saliva specimens as a non-invasive method of sample collection has been proposed to address these concerns (To et al. 2020).

In order to enhance the sensitivity and fidelity of RTPCR assays, a worthwhile strategy is to evaluate the potential of various viral components as probe targets and compare the relative performance of each. For instance, an early RT-PCR-based detection assay used probes against the ORF1b and $\mathrm{N}$ region of the viral genome (Chu et al. 2020). Subsequently, another study developed three novel assays aimed at the viral spike protein (S), nucleocapsid (N), and RNA-dependant RNA polymerase (RdRp)/Helicase (Hel) genes, out of which, the RdRp/Hel-based assay demonstrated no cross-reactivity with common respiratory pathogens as well as the lowest detection limit in vitro (Chan et al. 2020). Exploring such novel targets may help develop superior assays, which can improve the sensitivity and 
accuracy of detection. Furthermore, a comparative analysis by Nalla et al. evaluated seven different assay kits and reported the E-gene primer/probe set (as described by Corman et al. (2020)) and the N2 set (developed by the Division of Viral Diseases, Center for Disease Control and Prevention) as the most sensitive assays available. The importance of such independent assessments of reported/published studies needs to be underscored in healthcare crisis scenarios such as the present one, wherein resources are limited and must be judiciously allocated.

\subsection{Chest CT scans}

A few studies have also pointed out the liabilities of RT-PCR-based techniques. While some publications and in vitro assays may report excellent parameters of performance, clinical testing and feedback raise several red flags. A most elementary instance of this was reported in a case wherein two patients who were SARS-CoV-2 infected returned negative RT-PCR results, leading the authors to suggest chest CT scans as an essential part of clinical diagnosis (Li et al. 2020a). Similar issues with a high false-negative rate of RTPCR testing on patients over the course of disease progression and treatment have been reported separately as well (Li et al. 2020e). Such observations have promoted recommendations to include clinical parameters such as CT scan diagnosis as factors to be considered in addition to the aforementioned assays while making decisions on patient discharge, evaluation of recovery/response to treatment protocols. A retrospective study reached similar conclusions in favor of CT scans, ascribing a $97.2 \%$ sensitivity to $\mathrm{CT}$, as compared to $83.3 \%$ using RT-PCR (Long et al. 2020a).

At this juncture, we would like to emphasize a few recent studies which have underscored the potential of chest CT scans as a viable diagnostic technique. Work by Cao et al. and Dai et al. seeks to formulate a standard set of characteristic features indicative of a SARS-CoV-2 infection. The former, a systematic review and meta-analysis of infected patients, establishes the most common clinical symptoms as fever, cough, chest distress, fatigue, and dyspnea, along with major imaging features as ground-glass opacities and bilateral pneumonia (Cao et al. 2020a). The latter provides a more comprehensive treatment in which over two hundred patients were studied to report bilateral multiple lung lobes in both the periphery and lower portion of the lungs as being present in over $94.98 \%$ of the cases (Dai et al. 2020). Additionally, ground-glass opacities and vascular enhancement were identified as characteristic signatures, as well as fibrosis, air, trapping, and interlobular septal thickening. It is worthwhile to note that highly concordant observations have been made across different patient cohorts, and the general agreement between these is an indicator of the proposed technique's versatility and broad-spectrum applicability. A more extensive and detailed elucidation of the same may be found in the recent review by Hani et al. (Hani et al. 2020). Furthermore, timepoint-based CT scan data may be an invaluable tool to assess disease progression, treatment response, development of complications, and understanding the pathophysiology of the disease, as has been stressed by Bernheim et al. (2020). Additionally, an artificial intelligence (AI)-based platform has also been devised which utilizes a neural network to evaluate X-ray images and automatically detects SARS-CoV-2-infected positive specimens with an accuracy of $97.82 \%$ (Apostolopoulos and Bessiana 2020). Harnessing advances in computer science for medical diagnostics may serve as an essential tool to standardize and speed up the testing process. Similar applications of machine learning and AI to aid in the pandemic control efforts will be further elaborated in Sect. 4 .

\subsection{Antibody-based techniques}

The evident advantage of antibodies over nucleic acids amplification is higher specificity, accuracy, as well as rapid testing times since it does not require time-consuming amplification steps, nor involves cumbersome extraction/purification processes. A recent report has also highlighted that antibody titers may be a more reliable indicator of SARS-CoV-2 infections, especially for asymptomatic and suspected carriers who return negative RT-PCR results (Long et al. 2020b).

The classic Enzyme-linked Immunosorbent Assay (ELISA) may be readily adapted to serve as a SARSCoV-2 detection test. Accordingly, this has been employed against the recombinant viral nucleocapsid proteins and the recombinant viral spike proteins, which were used to detect the $\operatorname{IgM}$ and IgG antibody levels (Liu et al. 2020). This study established that spike protein-based assay would be more sensitive for detecting IgM. Along similar lines, the comparative performance of ELISA-based and Gold-immunochromatographic Assay (GICA)-based methods have also been evaluated (Xiang et al. 2020). The rapid testing times and high sensitivity observed posit serological assays as superior alternatives to RT-PCR on account 
of ease of sample collection (blood, which poses minimal risk to healthcare staff compared to swab samples) and low false-negative rates. In this regard, an efficient point-of-care device for diagnostic testing which combined the IgG-IgM testing platform with a testing time of fifteen minutes was recently reported ( $\mathrm{Li}$ et al. 2020f). While the repurposing of cross-reactive antibodies from highly similar species like the SARS$\mathrm{CoV}$ is a viable idea, an interesting report notes some pitfalls (Tian et al. 2020). Despite the relative identity between the SARS-CoV and the SARS-CoV-2, the authors point out that highly potent receptor binding site-targeting SARS-CoV neutralizing antibodies (like the CR3014 and m396) fail to engage the SARS-CoV-2 spike protein. This indicates that effective management of novel pathogens may necessitate the development of novel antibodies and those homology-based strategies to repurpose existing therapeutics should be rigorously vetted.

However, an over-reliance on antibody-based approaches is impractical. Designing nucleic acid probes is a far more straightforward process, and one much more rapidly deployable. Also, the detection of antibodies may be difficult in the early stages of infection, until a significant titer of $\operatorname{IgG} / \operatorname{IgM}$ has accumulated in circulation. This may contribute towards significant false-negative rates during largescale screenings, especially when periodic sampling and extended observation of test subjects may not be feasible. Hence, despite the salient advantages of antibody-based techniques as discussed above, several assay kits and field-testing protocols have remained in the domain of PCR amplification-based methods. Accordingly, our object of focus for the next section will be one such recently evolved technology, loopmediated isothermal amplification (LAMP).

\section{$2.4 \quad R T-L A M P$}

LAMP-based protocols enable the efficient amplification of nucleic acids at a single point temperature. This feature makes it a strong contender for direct field applications, since incorporating the thermal cycling steps in PCR assays has traditionally been a significant limitation for point-of-care devices. LAMP's inherent advantages are not limited to isothermal operability alone. This robust technique works efficiently even with crude sample preparations, compared to traditional PCR methods, and also offers a very high amplification efficiency since it is not limited by a doubling-per-cycle threshold (Becherer et al. 2020).
We wish to highlight two particular tests, both of which report colorimetric detection capability - a major boon for point-of-care devices. A team led by Di Liu and Jing Yuan reported RT-LAMP assays for SARS$\mathrm{CoV}-2$ detection, with ORF1ab and $\mathrm{S}$ genes as the primer-probe targets (Yan et al. 2020). The work claims complete detection within $60 \mathrm{~min}$, using a colorimetric detection system that employs fluorescent calcein, where a color change from orange to green indicates positive reactions (visually detectable by the naked eye). Another effort by Renfei $\mathrm{Lu}$ et al. involving primers targeted at the RdRp utilizes cresol red (a $\mathrm{pH}$-sensitive indicator dye) for the assay readout (Lu et al. 2020). Since a proceeding amplification can progressively change the buffer $\mathrm{pH}$ from alkaline to acidic, a color change from burgundy to orange/yellow signals a positive reaction. These innovations in assay readout methodology imply a significant advancement since they make it possible to have even untrained healthcare workers administer, conduct, and interpret diagnostic tests.

A noteworthy instance of adapting RT-LAMP for a truly bedside point-of-care application is the innovative closed-tube test developed by Song and colleagues (E1Tholoth et al. 2020). Combining straightforward sample collection with single or two-step RT-LAMP amplification protocols, along with a visual detection system based on LCV (leucocrystalviolet - an intercalating agent which colorimetrically detects doublestranded LAMP amplicons), this device is a readily deployable and highly portable testing method that promises to be a cheap and reliable alternative suitable for all testing environments.

\subsection{Emerging techniques: reactive polymers and CRISPR/Cas-based systems}

This subsection is devoted to a couple of non-conventional detection methods, which may well serve as a versatile platform in the future. The first is a reactive polymer-grafter device which utilizes antibodies to detect dsRNA (Ku et al. 2020). A suitable polymercoated surface-reactive poly(pentafluorophenyl acetate) in this case is used to immobilize $\mathrm{J} 2$ antibodies on the surface. Following the preparation of the platform, it may be directly applied to detect dsRNA as the $\mathrm{J} 2$ antibodies may bind dsRNA molecules specifically. The principal advantage, in this case, is that the antibody binding is sequence-independent; hence the platform may serve as a universal virus detection unit. However, it may be noted that such one-size-fits-all 
approaches suffer from an inherent lack of specificity. In this case, the sequence-independent nature of detection suggests a high possibility of false positives. Such a scenario would necessitate secondary tests using established protocols for reliable confirmations of diagnosis, thereby positing the $\mathrm{J}$ antibodies-based technique as a potential preliminary screening step, rather than as a standalone entity.

The second major innovation involves the use of CRISPR-Cas-based techniques for the detection of viral nucleic acids. Recently, such CRISPR-based detection systems, notably SHERLOCK and DETECTR, were reported as emerging diagnostic tools. The fundamental principle involves the activation of a suitable Cas variant (Cas13 for SHERLOCK, Cas12a for DETECTR) by binding of the appropriate target sequence (ssRNA or mRNA for Cas13 and dsDNA for Cas12a), which enables the Cas variants to promiscuously cleave and degrade surrounding ssRNA and ssDNA, respectively. The ssRNA/ssDNA meant for the latter reaction may be coupled with a quenchable fluorophore, which produces a quantifiable signal upon being released by cleavage. Hence, the detection of the exact target sequence is indicated by an assay readout in the form of a fluorescence signal. This system allows for rapid and accurate detection of viral RNA samples since amplification of these (along with suitable modifications as per the system used) can then allow for precise targeting and detection by the Casbased assay described above. This remarkable ability has been recently demonstrated by using the DETECTR system as a diagnostic tool for SARS$\mathrm{CoV}-2$ infections in a rapid lateral flow assay incorporating RT-LAMP using nasal swab samples (Broughton et al. 2020). Additionally, a series of reports may be found on the Broad Institute's website (https://www.broadinstitute.org/news/enablingcoronavirus-detection-using-crispr-cas13-open-accesssherlock-research-protocols-and), wherein a team comprising of Feng Zhang, Omar Abudayyeh, and Jonathan Gootenberg aim to develop paper-based platforms for rapid and straightforward SARS-CoV-2 detection (B Institute 2020).

\section{Treatment strategies for SARS-CoV-2 infections}

In this section, we endeavor to review some of the established and emerging treatment paradigms which are being currently employed or recommended on the basis of published literature and empirical evidence from clinical case studies. The major ones have been pictorially represented in figure 2 .

\subsection{Drugs-based conventional approaches}

Amongst drug-based treatment strategies, the broadspectrum antiviral chloroquine and its derivative hydroxychloroquine have received much attention. As early as February 2020, both remdesivir and chloroquine were identified as potential inhibitors of the SARS-CoV-2 in vitro (Wang et al. 2020b). Remdesivir, a potential candidate against Ebola, SARS-CoV, and MERS-CoV, is an adenosine analog that inhibits viral replication. On the other hand, chloroquine targets endosomal fusion by elevating the endosomal $\mathrm{pH}$, alongside interfering with the glycosylation of ACE2. The rationale for using chloroquine is further buttressed by a variety of possible antiviral effector functions (Devaux et al. 2020). Experimental evidence for a putative mechanism was provided by structural data and molecular modeling approaches, where a conserved ganglioside binding domain at the $\mathrm{N}$ terminus of the viral $\mathrm{S}$ protein was identified as the target for chloroquine and hydroxychloroquine. This inhibition of viral attachment and entry appears to explain chloroquine and its derivative hydroxychloroquine's apparent efficacy against SARS-CoV-2 infections (Fantini et al. 2020). However, it is important to recognize that evidence for the clinical benefits of these much-touted drugs is contentious at best and unreliable at worst. While hydroxychloroquine and azithromycin were earlier claimed as potentially effective drugs against SARS-CoV-2 infections, the reporting study has since come under criticism for the lack of a control group and incomplete descriptors of actual clinical outcomes and patient inclusion criteria (Gautret et al. 2020). A separate randomized trial enrolling 62 patients did, however, report a statistically significant positive effect of hydroxychloroquine treatment in alleviating patient symptoms (Chen et al. 2020c). These claims are offset by three additional reports, none of which conclude any significant benefit from this treatment method (Borba et al. 2020; Magagnoli et al. 2020; Mahevas et al. 2020). An emerging class of candidate drugs are corticosteroids, which have recently generated great interest in the context of COVID-19 treatment approaches. While early skepticism did reign over corticosteroids usage, considering its propensity to elicit adverse reactions in severely ill patients, evidence from recent clinical trials and metaanalyses have hinted at significant benefits from this 


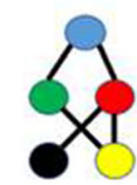

Literature analysis and $\mathrm{Al} / \mathrm{ML}$-driven platforms

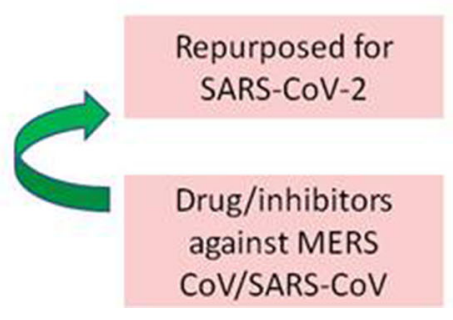

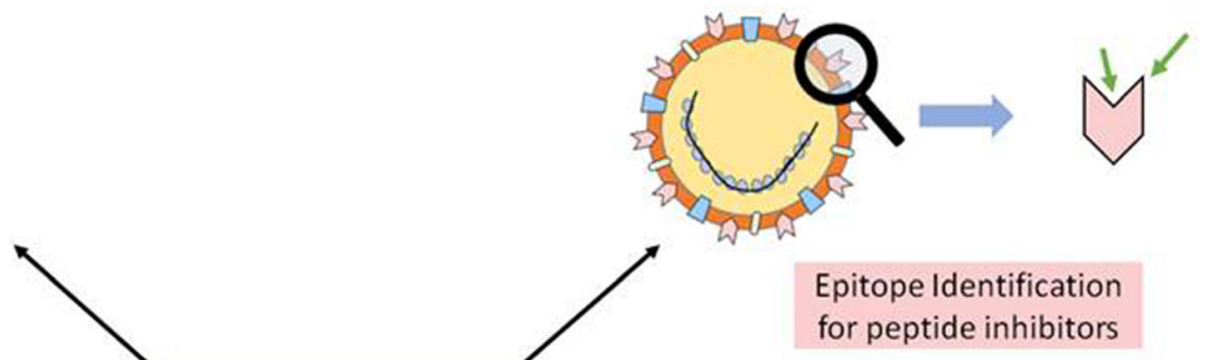

Drug Discovery for SARS-COV-2

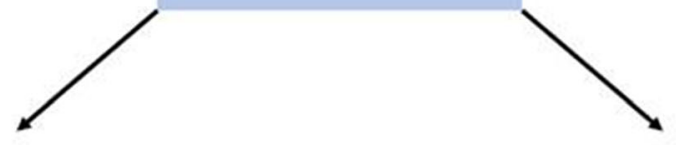

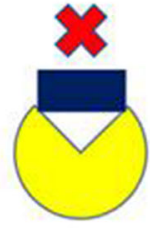

Molecular Docking

Figure 2. Some established and emerging treatment paradigms being currently employed or recommended on the basis of published literature and empirical evidence from clinical case studies.

drug for the management of critically ill patients. This has led to a growing advocacy of corticosteroids as a leading candidate in the global effort against COVID19 (Halpin et al. 2020; Ma et al. 2020b; Sanders et al. 2020; Singh et al. 2020; Yang et al. 2020b; Ye et al. 2020; Zha et al. 2020).

Emerging technologies powered by AI offer systematic and highly modular solutions for urgent drug discovery and identification requirements. A study published in The Lancet (Richardson et al. 2020) employed Benevolent AI, a platform for AI-guided drug discovery and clinical development, to offer suggestions for drugs targeted explicitly at SARS-CoV2. Using a systematic knowledge graph, the platform was able to identify baricitinib, a Janus kinase inhibitor that binds the AAK1 (AP2-associated protein kinase 1, a regulator of endocytosis). Section 4 will deal with this domain in greater detail.

\subsection{Docking simulations and molecular dynamics- based approaches}

Powerful computational resources can greatly enhance our ability to rapidly screen for drugs and inhibitory agents against emerging pathogens. The SARS-CoV-2 protease has been a popular target for such docking simulations and molecular dynamics-based studies (Liu and Wang 2020), in part due to the recent availability of its structure. A broad screening effort of over 1.3 billion compounds from the ZINC15 database used an upgraded docking protocol (termed DeepDocking) to identify over a thousand such potential inhibitors of the SARS-CoV-2 protease (Ton et al. 2020). A more systematic approach along similar lines screened 687 million compounds via docking, followed by molecular dynamics simulations to evaluate ligand-binding energies, stability, toxicity assessment, as well as off-target binding (Fischer et al. 2020). Alongside such screening efforts for existing molecules, the identification of promising lead compounds that could serve as scaffolds for further modification is an essential step to enable the development of novel drugs. This requirement was addressed by a recent in-silico study, which provided a clustered report of twenty short-listed compounds into three groups, each of which could serve as leads for the development of SARS-CoV-2 inhibiting drugs (Ortega et al. 2020).

While the ability of advanced computational facilities to virtually screen multitudinous drugs and compounds - numbering anywhere from a few thousand to even a billion - might be unmatched by traditional methods, the importance of physical assay-based screens is indispensable. The recent report of a largescale $(12,000+$ compounds) repositioning survey of FDA-approved and under-trial drugs in the context of 
SARS-CoV-2-targeted antivirals attests to this (Riva et al. 2020). Following an initial selection based on inhibition of cytopathic effects, an orthogonal validation assay was used to delineate the compounds which specifically inhibited viral replication. This study also provided classification and categorization of target annotations and drug target genes for the short-listed drugs. The identification of these specific domains can help similar such efforts in the future to be more focussed on specific drug types and targets that have been identified to exert the most promising antiviral effect on SARS-CoV-2. Another notable effort combined virtual screening methods with high-throughput assays to enable the rapid identification of promising drug candidates (Jin et al. 2020). Using a FRET-based assay to assess the enzymatic activity of SARS-CoV-2 protease, over 10,000 compounds were screened for inhibitory effects on the enzyme. Additionally, the authors extensively analyzed a compound termed N3, initially developed using computer-aided drug design as an inhibitor of multiple coronavirus proteases. Following molecular docking, kinetic analysis of the protease, and determination of its crystal structure with the SARS-CoV-2 protease, the inhibitory effects of N3 were ascertained. The comprehensive approach adopted by this study is an exemplar model for similar investigations. The obvious merits of virtual screening methods notwithstanding, strong emphasis needs to be laid on developing high-throughput biochemical and cellular assays for experimental validation of pharmacologically active compounds. The importance of this cannot be overstated, as such empirical evidence helps establish a reliable standard for ascertaining the actual merits of proposed therapeutic approaches, which may, at least at the current stage of research, only be supplemented by computational studies.

\subsection{Plasma therapy}

Alongside treatment with drugs, convalescent plasma (CP) therapy is being advocated as a clinically effective practice. The procedure involves using blood plasma obtained from recovered patients as an adaptive immune therapy for critical cases. The underlying principle at work is that the donor plasma contains a high titer of antibodies that are effective against the pathogen, hence provides an immunity boost to the recipient. $\mathrm{CP}$ has been advocated as an alternative therapy for SARS-CoV-2 infections (Chen et al. 2020a) and therapeutic plasma exchange has been recommended as a suitable strategy to deal with the often associated acute respiratory distress syndrome (ARDS) (Keith et al. 2020). An initial four-patient sample established that CP could have therapeutic benefits for critically ill patients (Zhang et al. 2020a). While all four patients showed a progression towards negative RT-PCR results, the authors of the study stress that it would be difficult to rule out confounding factors as well as the effects of additional supportive care and treatments such as antiviral drugs and intravenous immunoglobulin. A similar study involving a ten-patient cohort demonstrated that $\mathrm{CP}$ dosages could either increase or maintain the existing levels of neutralizing antibodies in the recipients (Duan et al. 2020). Additionally, the clinical symptoms were also observed to improve progressively, leading up to the absence of viremia. The study highlights two other salient outcomes - one, that $\mathrm{CP}$ appeared to be tolerated well by the recipients without adverse reactions, and two, that transfusion of $\mathrm{CP}$ alleviated inflammation. It is important to note, however, that these studies need to be further supplemented by rigorous and controlled clinical trials to discount both the effects of external factors, as well as establish proper protocols for $\mathrm{CP}$ therapy concerning the dosage, duration, and other appropriate parameters.

\subsection{Managing cytokine storm responses}

Among the several complications associated with SARS-CoV-2 infections, cytokine storm responses, which are a by-product of immune hyperactivation and loss of regulatory control over pro-inflammatory cytokines, pose a major risk for patient survival and may lead to rapid deterioration of patient health. The stimulation of CD-4+ T-cells to differentiate into Th1 helper cells along with IL-6, interferon-gamma, and GM-CSF (granulocyte-macrophage colony-stimulating factor) production, amongst other proinflammatory cytokines, are considered as the steps leading up to a cytokine storm-like condition. The persistently high levels of certain cytokines like IP-10, MCP-3, and IL1ra may be characteristic of such an onset, and these may be developed as screening parameters to ascertain the same (Yang et al. 2020a).

Extensive efforts to safely manage this condition have been undertaken. For instance, the use of an IL6 receptor antagonist drug such as tocilizumab has been suggested, since the IL- 6 has been identified as a key driver of cytokine storm response (Zhang et al. 2020b). Writing in The Lancet, Mehta et al. also recommend similar IL-6 targeted strategies (Mehta 
et al. 2020). While a previous study had failed to establish a significant connection between the administration of corticosteroids and improved treatment outcomes (Zha et al. 2020), Mehta et al. recommend consideration of such a course of treatment to tackle hyperinflammation. However, there is no concrete evidence to support corticosteroid-based treatment as being of overall therapeutic value, in addition to the associated risks of lung injury (Russell et al. 2020). A detailed review also suggests several strategies by which cytokine storm responses may be dealt with, including the use of the abovecited IL-6R agonist tocilizumab. Glycyrrhetinic acid, another IL-6 and STAT3 signaling inhibitor has been suggested as a potential candidate. Additionally, mesenchymal stem cell infusions have been highlighted due to the immunomodulatory and anti-inflammatory potential of these cells (Cheng et al. 2020). An alternate approach to managing cytokine storm response has been suggested in the form of artificial blood purification systems. Essentially, this involves using an external filtration-cum-treatment setup to modulate the various factors and chemokines responsible for orchestrating the proinflammatory response. This may be achieved by the use of scavenging inflammatory mediators and plasma exchange. At the same time, continuous venovenous hemofiltration units may be employed, as demonstrated for the successful containment of cytokine storm responses in critically afflicted H7N9 influenza patients (Zhang et al. 2020d). The merits of blood purification therapy for alleviating similar symptoms in SARS-CoV-2 infected patients have also been demonstrated by a recent study from Wuhan involving three patients (Ma et al. 2020a).

\subsection{Other emerging treatment strategies}

Strategies aimed at halting viral entry are not limited to drug-based approaches alone, as peptide inhibitors can play a vital role in achieving similar effects. To this end, the team led by Shibo Jiang and $\mathrm{Lu} \mathrm{Lu}$ has built upon previous work that generated fusion inhibitors against the SARS-CoV spike protein's HR1 region to design HR2P as a fusion inhibitor against SARS-CoV2, as well as EK1 (a pan-coronavirus fusion inhibitor). In a follow-up study, the team generated a series of EK1-derived lipopeptides to determine the ones exhibiting the most potent inhibition of fusion (variant identified as EK1C4). Suitable formulations of such peptide preparations, as suggested by the authors, may be a valuable treatment resource for SARS-CoV-2 infections (Xia et al. 2020a; Xia et al. 2020b).

The value of mesenchymal stem cell transplants in improving patient health for SARS-CoV-2 infections was demonstrated in a clinical study involving seven patients (Leng et al. 2020). Several outcomes were characteristic of the suggestions made by Cheng et al. as mentioned earlier, including immunomodulatory effects, an attenuating effect on proinflammatory cytokines, and elevated IL-10 levels. An interesting observation made by the authors of the clinical study was that such mesenchymal stem cells lacked both ACE2 and TMPRSS2 gene expression, which could effectively render them immune to SARS-CoV-2 infection. The possible benefits of cell therapy-based therapeutic approaches may be immense and have been explored at length in a recent review (Khoury et al. 2020).

The potential of melatonin as an adjuvant in clinical treatment on account of its immune-enhancing, antiinflammatory, and anti-oxidative effects has been extolled at length in a recent review (Zhang et al. 2020c). Another study focused on the antagonists of the lipid-dependant attachment process of viral particles to host cells (Baglivo et al. 2020). Given that SARS-CoV-2 utilizes structures such as lipid rafts to mediate its entry process, the authors recommend exploring the possibilities of employing substances like cyclodextrin and sterols to interfere with such viral attachment and entry-enabling mechanisms. Along similar lines of conjecturing prospective therapeutic candidates, EZH2-mediated H3K27me3 at ACE2 promoter regions has been demonstrated to inhibit the expression of ACE2 receptors in mammalian cell lines, as indicated by data from RNA-Seq and CHIP-Seq experiments (Li et al. 2020d).

A major cause of patient mortality in severe SARSCoV-2 infections is the ARDS as well as coagulopathy. Fibrinolytic therapy to target the fibrin deposition in the pulmonary vasculature (a potential contributor towards ARDS) has been shown to improve survival, along with administration of tissue plasminogen activators (which converts plasminogen to plasmin, that can further breakdown blood clots). This strategy has been shown to improve conditions in a three patient study, and further clinical trials to ascertain its applicability as a standard clinical practice for critically ill SARS-CoV2 infected patients with ARDS have been recommended (Wang et al. 2020a).

The development of effective prophylactic agents is an essential component of a comprehensive approach towards tackling a global pandemic of this scale and 
severity. The importance of administering prophylaxis to frontline healthcare workers, screening personnel, and researchers, among others, cannot be overstressed, as the safety and continued productivity (which necessitates sound health) of these key players is paramount to maintain any sustained effort at containing the pandemic and providing healthcare and treatment of adequate quality to affected patients. In this regard, a concise review of established protocols and proposed strategies currently under scrutiny has been recently published in the form of correspondence (Agrawal et al. 2020).

Considering the rapidly evolving status of COVID19 treatment protocols, it is of utmost importance to critically evaluate the most up-to-date evidence available while designing guidelines for clinical practice. Of equal pertinence are social awareness campaigns and the regular dissemination of accurate information regarding clinically proven treatment protocols. This assumes greater importance in light of a growing inclination towards scientifically unsubstantiated claims based on anecdotal/circumstantial evidence or misrepresented facts placed out of context. We further present a brief, non-exhaustive listing (table 1) of leading therapeutic agents frequently associated with COVID-19 treatment, as well as the current opinion of the scientific community regarding each of these, based on the evidence from reported/ongoing clinical trials.

\section{Emerging technologies for biomedical research: artificial intelligence and machine learning}

The fields of Artificial Intelligence (AI) and Machine Learning (ML) have undergone tremendous growth in scope and popularity in the recent past, establishing them as important paradigms for future innovation. More importantly, the development of modules suitable for biomedical applications has transformed AI and ML into attractive tools for the current global effort to tackle the SARS-CoV-2 pandemic.

With regard to infectious diseases, AI-based platforms may be employed to monitor outbreak and clustering trends, as well as evaluate the impact of containment programs and carry out risk assessment with minimal human intervention. The AI-based service BlueDot deserves a noteworthy mention of having raised one of the earliest alarms on SARSCoV-2's potential for broad global spread (Bogoch et al. 2020). Additionally, these hold immense promise for dynamic situational monitoring of patients in real-time, enabling critical evaluation and optimization of trial treatment protocols in a much more efficient manner. ML-based solutions can be expected to consistently enhance and refine such designs over time, provided they are trained on a readily updated and expertly-curated dataset. This represents an important caveat, as the efficacy and accuracy of ML-based pattern prediction and recognition may be maintained only if the training dataset is free of biases and a diverse range of scenarios are well-represented (Fitzpatrick et al. 2020). We had previously referred to the work by Apostolopoulos and Bessiana, which could screen for SARS-CoV-2 infections using X-ray images. This has been supplemented by a neural network-based platform using $\mathrm{X}$-ray images, with a maximum prediction accuracy of 98\% (Narin et al. 2020). Furthermore, an automated AI-based protocol to identify SARS-CoV-2 infections and distinguish these from other lung diseases or community-acquired pneumonia has been recently formulated ( $\mathrm{Li}$ et al. 2020a, b, c, d, e, f). It must be noted that both these models were trained on datasets consisting of actual patient X-ray images, which is in line with a point we have reiterated above - that training datasets should necessarily be accurate, well-represented, and as free of biases as possible. An exciting new development reported by the Broad Institute's Sabeti lab concerns an MLbased platform for automated Cas13-based SHERLOCK assay design (Metsky et al. 2020). Such an advance represents a potential breakthrough, as highly optimized and expanded open-access platforms of this nature can aid researchers the world over in rapidly designing standardized tests for novel and emerging pathogens using just the knowledge about their genomic sequence. This can help accelerate the deployment of rapid responses to outbreaks and thereby greatly enhance early screening and containment efforts. Understandably, a confident reliance on such automated processes may only be possible once multiple field applications have validated the same and demonstrated similar, if not superior, performance in comparison with existing assay design pipelines.

Section 3.1 of this review highlights the study which determined baricitinib as a potential drug against SARS-CoV-2 (Richardson et al. 2020). Writing in The Lancet, the same team extended this workflow to develop more comprehensive treatment strategies aimed at shortlisting drugs that offered both antiviral as well as anti-inflammatory effects (Stebbing et al. 2020). The highly modular nature of AI-based knowledge graphs, an example of which has been 
Table 1. Leading therapeutic agents against COVID-19, evaluated and described across common parameters

\begin{tabular}{|c|c|c|}
\hline Drug & Parameters & Details \\
\hline \multirow[t]{5}{*}{ Azithromycin } & Status/Remarks & $\begin{array}{l}\text { No improvement on clinical outcomes, but no significant increase in detrimental } \\
\text { side-effects either }\end{array}$ \\
\hline & $\begin{array}{l}\text { Drug type/ } \\
\text { Original purpose }\end{array}$ & Antibiotic \\
\hline & $\begin{array}{l}\text { Mode of } \\
\text { Administration }\end{array}$ & Oral/Intravenous \\
\hline & $\begin{array}{l}\text { Mechanism of } \\
\text { Action }\end{array}$ & Inhibits mRNA translation by binding to 50 s subunit of bacterial ribosome \\
\hline & References & Furtado et al. (2020), Oldenburg and Doan (2020) \\
\hline \multirow[t]{5}{*}{ Baricitinib } & Status/Remarks & $\begin{array}{l}\text { Improvement in patient status observed, no adverse side-effects reported. } \\
\text { Currently in phase III clinical trials conducted by Eli Lilly and Co }\end{array}$ \\
\hline & $\begin{array}{l}\text { Drug type/ } \\
\text { Original purpose }\end{array}$ & For rheumatoid arthritis treatment \\
\hline & $\begin{array}{l}\text { Mode of } \\
\text { Administration }\end{array}$ & Oral \\
\hline & $\begin{array}{l}\text { Mechanism of } \\
\text { Action }\end{array}$ & Janus kinase inhibitor. Shows anti-inflammatory activity \\
\hline & References & Cantini et al. (2020) \\
\hline \multirow[t]{5}{*}{$\mathrm{CD} 24 \mathrm{Fc}$} & Status/Remarks & $\begin{array}{l}\text { In phase III clinical trials. Preliminary results suggest effective management of } \\
\text { COVID-associated symptoms }\end{array}$ \\
\hline & $\begin{array}{l}\text { Drug type/ } \\
\text { Original purpose }\end{array}$ & nonpolymorphic regions of CD24 attached to the Fc region of human IgG1 \\
\hline & $\begin{array}{l}\text { Mode of } \\
\text { Administration }\end{array}$ & Intravenous \\
\hline & $\begin{array}{l}\text { Mechanism of } \\
\text { Action }\end{array}$ & Immunomodulator, tempers inflammatory responses \\
\hline & References & OncoImmune (2020) \\
\hline \multirow[t]{5}{*}{ Colchicine } & Status/Remarks & $\begin{array}{l}\text { Has been hypothesized to address inflamatory responses in COVID-19 infection, } \\
\text { but concerns regarding adverse side-effects have been raised. Currently under } \\
\text { clinical trial }\end{array}$ \\
\hline & $\begin{array}{l}\text { Drug type/ } \\
\text { Original purpose }\end{array}$ & Anti-gout agent \\
\hline & $\begin{array}{l}\text { Mode of } \\
\text { Administration }\end{array}$ & Oral \\
\hline & $\begin{array}{l}\text { Mechanism of } \\
\text { Action }\end{array}$ & $\begin{array}{l}\text { Inhibits microtubule polymerization, proinflammatory responses, neutrophil } \\
\text { migration, and mitosis }\end{array}$ \\
\hline & References & Cumhur Cure et al. (2020), Dalili (2020) \\
\hline \multirow[t]{5}{*}{ Dexamethasone } & Status/Remarks & $\begin{array}{l}\text { Shown to lower mortality rate in a recent trial, currently being provisionally } \\
\text { approved for patient treatment in certain regions. May be effective in critically ill } \\
\text { patients }\end{array}$ \\
\hline & $\begin{array}{l}\text { Drug type/ } \\
\text { Original purpose }\end{array}$ & Corticosteroid \\
\hline & $\begin{array}{l}\text { Mode of } \\
\text { Administration }\end{array}$ & Oral/Intravenous/Intramuscular \\
\hline & $\begin{array}{l}\text { Mechanism of } \\
\text { Action }\end{array}$ & Immunosuppresant. Shows anti-inflammatory effects \\
\hline & References & Horby et al. (2020) \\
\hline \multirow[t]{5}{*}{ EIDD-2801 } & Status/Remarks & $\begin{array}{l}\text { Potent antiviral activity observed in mouse models and primary human cells. } \\
\text { Currently under phase } 2 \text { clinical trial }\end{array}$ \\
\hline & $\begin{array}{l}\text { Drug type/ } \\
\text { Original purpose }\end{array}$ & Antiviral drug. Nucleoside derivative N4-hydroxycytidine \\
\hline & $\begin{array}{l}\text { Mode of } \\
\text { Administration }\end{array}$ & Oral \\
\hline & $\begin{array}{l}\text { Mechanism of } \\
\text { Action }\end{array}$ & Interferes with viral replication by introducing mutations \\
\hline & References & Ridgeback Biotherapeutics (2020), Sheahan et al. (2020) \\
\hline
\end{tabular}


Table 1 (continued)

\begin{tabular}{|c|c|c|}
\hline Drug & Parameters & Details \\
\hline \multirow[t]{5}{*}{ Favipiravir } & Status/Remarks & $\begin{array}{l}\text { Clinical studies show faster viral clearence and improvement in chest imaging. A } \\
\text { recent clinical trial from India by Glenmark showed faster and more effective } \\
\text { recovery rate }\end{array}$ \\
\hline & $\begin{array}{l}\text { Drug type/ } \\
\text { Original purpose }\end{array}$ & Pyrazinecarboxamide derivative \\
\hline & $\begin{array}{l}\text { Mode of } \\
\text { Administration }\end{array}$ & Oral/Intravenous \\
\hline & $\begin{array}{l}\text { Mechanism of } \\
\text { Action }\end{array}$ & Inhibits the viral RNA-dependent RNA polymerase \\
\hline & References & Glenmark (2020), Irvani (2020) \\
\hline \multirow[t]{5}{*}{ Hydroxychloroquine } & Status/Remarks & $\begin{array}{l}\text { Discontinued as a recommended drug for treatment. Clinical studies show no } \\
\text { significant benefit for patients. Adverse cardiovascular effects have been } \\
\text { reported. However, the study by Mehra et al., claiming no significant benefits of } \\
\text { HCQ administration, has since been withdrawn }\end{array}$ \\
\hline & $\begin{array}{l}\text { Drug type/ } \\
\text { Original purpose }\end{array}$ & Chloroquine derivative. Antimalarial drug \\
\hline & $\begin{array}{l}\text { Mode of } \\
\text { Administration }\end{array}$ & Oral \\
\hline & $\begin{array}{l}\text { Mechanism of } \\
\text { Action }\end{array}$ & Increases lysosomal pH. Also dampens inflammatory response \\
\hline & References & $\begin{array}{l}\text { Chen et al. (2020c), Gautret et al. (2020), Li et al. (2020a, b, c, d, e, f), Mahevas } \\
\text { et al. (2020), WHO (2020b) }\end{array}$ \\
\hline \multirow[t]{5}{*}{ Ivermectin } & Status/Remarks & $\begin{array}{l}\text { Emerging candidate against COVID-19. Initial concerns were raised over its high } \\
\text { effective dosage concentration by Caly et al., but this is being explored as a safer } \\
\text { and more effective alternative to HCQ }\end{array}$ \\
\hline & $\begin{array}{l}\text { Drug type/ } \\
\text { Original purpose }\end{array}$ & Avermectin derivative \\
\hline & $\begin{array}{l}\text { Mode of } \\
\text { Administration }\end{array}$ & Oral/topical \\
\hline & $\begin{array}{l}\text { Mechanism of } \\
\text { Action }\end{array}$ & Targets ligand-gated ion channels of invertebrate neural cells \\
\hline & References & Caly et al. (2020), Gupta et al. (2020), Heidary and Gharebaghi (2020) \\
\hline \multirow[t]{5}{*}{ Lopinavir-ritonavir } & Status/Remarks & $\begin{array}{l}\text { Clinical studies have demonstrated no significant benefits of lipinavir-ritonavir in } \\
\text { COVID-19 affected patients }\end{array}$ \\
\hline & $\begin{array}{l}\text { Drug type/ } \\
\text { Original purpose }\end{array}$ & Antiretroviral drug \\
\hline & $\begin{array}{l}\text { Mode of } \\
\text { Administration }\end{array}$ & Oral \\
\hline & $\begin{array}{l}\text { Mechanism of } \\
\text { Action }\end{array}$ & HIV protease inhibitor \\
\hline & References & Cao et al. (2020b), WHO (2020b) \\
\hline \multirow[t]{5}{*}{ Remdesivir } & Status/Remarks & $\begin{array}{l}\text { Significant benefits from administration of this drug are doubtful. Clinical studies } \\
\text { have reported a marginal improvement in critically ill patients }\end{array}$ \\
\hline & $\begin{array}{l}\text { Drug type/ } \\
\text { Original purpose }\end{array}$ & Nucleoside analog \\
\hline & $\begin{array}{l}\text { Mode of } \\
\text { Administration }\end{array}$ & Intravenous \\
\hline & $\begin{array}{l}\text { Mechanism of } \\
\text { Action }\end{array}$ & Inhibits the viral RNA-dependent RNA polymerase \\
\hline & References & Grein et al. (2020), Wang et al. (2020a, b) \\
\hline
\end{tabular}


Table 1. (continued)

\begin{tabular}{|c|c|c|}
\hline Drug & Parameters & Details \\
\hline \multirow[t]{5}{*}{ Tocilizumab } & Status/Remarks & $\begin{array}{l}\text { Studies appear to recommend this drug for critically ill patients, especially for the } \\
\text { alleviation of COVID-19-associated pneumonia and cytokine storm management }\end{array}$ \\
\hline & $\begin{array}{l}\text { Drug type/Original } \\
\text { purpose }\end{array}$ & Humanized monoclonal antibody against IL-6 receptor \\
\hline & $\begin{array}{l}\text { Mode of } \\
\text { Administration }\end{array}$ & Intravenous \\
\hline & $\begin{array}{l}\text { Mechanism of } \\
\text { Action }\end{array}$ & Immunosuppressant \\
\hline & References & Biran et al. (2020), Guaraldi et al. (2020), Luo et al. (2020), Zhang et al. (2020b) \\
\hline
\end{tabular}

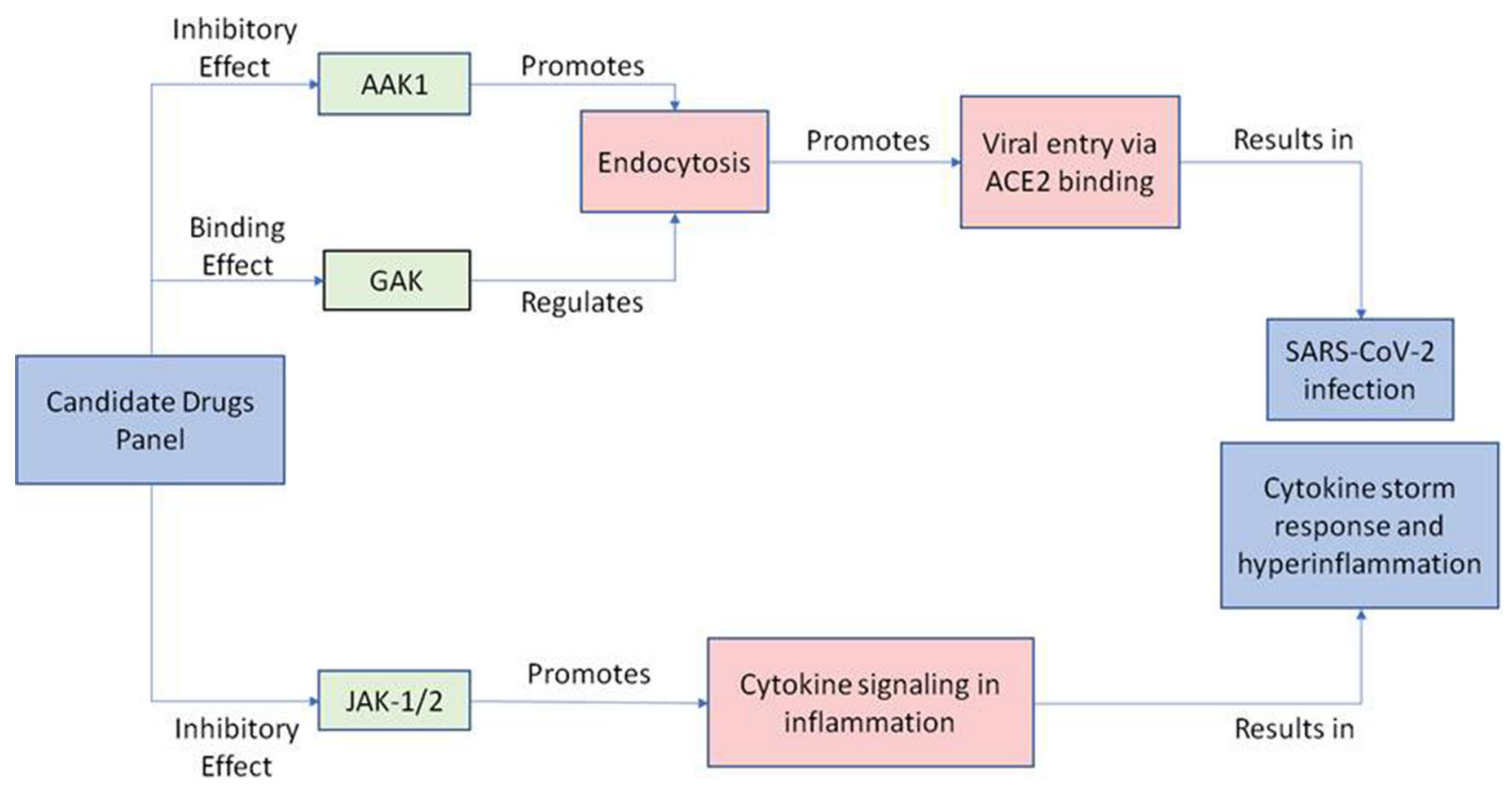

Figure 3. An example illustrating the highly modular nature of AI-based knowledge graphs.

shown in figure 3, posit these as versatile tools for efforts aimed at rapid drug prediction from extensive libraries. A similar report was published which used a drug repositioning framework employing ML and statistical analysis. The results were validated by testing its predictions for MERS-COV and SARS-COV, which were shown to be in line with the experimentally observed results (Ge et al. 2020). A reverse vaccinology study employing Vaxign-ML (a machine learningbased application) was recently carried out (Ong et al. 2020). The basic workflow involves a bioinformatic analysis of the genome/proteome, based upon which suitable targets are scored. Given the number of existing and reported studies targeting the viral spike protein (which also received the highest score using Vaxign-ML), the authors of this study decided to focus on the nsp3 which was ascribed the second-highest score by the aforementioned algorithm. It appears that vaccine candidate identification efforts stand to benefit from such ML-driven analysis, which may have an inherent edge in unearthing unconventional and generally non-obvious targets offering similar or superior outcomes as compared to those determined using traditional workflows or established tenets. 


\section{Vaccine development for SARS-CoV-2}

Considering the highly contagious nature of the SARSCoV-2 infection, the only long-term sustainable solution is the development of robust vaccination protocols. In this brief section, we wish to draw the reader's attention to some innovative, cutting-edge approaches towards determining potential vaccine candidates.

An approach based on comparing the human and viral proteomes to search for pentapeptide sequences unique to the SARS-CoV-2 was proposed by Guglielmo Lucchese, as these would be expected to have high immunogenicity as well as specificity (Lucchese 2020). Immunoinformatics-guided investigations may also play a significant role in the identification of suitable target epitopes, as shown by two recent papers (Ahmed et al. 2020; Baruah and Bose 2020). Baruah and Bose screened the SARS-CoV-2's surface glycoprotein for CTL and B-cell epitopes, further supplemented by molecular dynamics simulations to adjudge the interactions of the former with MHC Class I types majorly represented in the Chinese population (Baruah and Bose 2020). The work by Ahmed et al. incorporated insights from the study of immunogenic SARS-CoV proteins and B/T-cell epitopes derived from the same to obtain a set of such epitopes for the SARS-CoV-2, which have also been verified to be invariable amongst the published SARSCoV-2 genomes, thereby making these attractive targets (Ahmed et al. 2020). Another notable effort undertook an in-silico approach aimed at designing a multi-epitope vaccine candidate by predicting B/T-cell epitopes based on analysis of the viral nucleocapsid, ORF3a, and membrane protein (Enayatkhani et al. 2020). It is conceivable that a comprehensive screen of epitopes identified in the above-cited (and other related) literature in suitable animal models may yield lead candidates for vaccine trials.

Data generated by previous studies on the SARS$\mathrm{CoV}$ significantly facilitates current vaccine development efforts against the SARS-CoV-2. For instance, an analysis of the antigenic and glycosylation variation between SARS CoV and SARS-CoV-2 revealed that while several novel glycosylation sites were observed in the receptor-binding domain of SARS-CoV-2, the structure of the glycoprotein showed no significant divergence (Kumar et al. 2020). Additionally, despite the antigenic variability between both the strains, certain CTL epitopes were found to be conserved, suggesting that existing peptide-based vaccine candidates against the SARS$\mathrm{CoV}$ could be repurposed for testing against
SARS-CoV-2. This observation is supplemented by a recently published report, wherein ConformationalEpitope BLAST (which identifies antigenic similarity of a new pathogen to existing ones) was used to identify cross-reactive epitopes in the ACE2 receptor binding region of SARS-CoV-2's S protein (Qiu et al. 2020). Along similar lines, polyclonal antibodies against the SARS-CoV receptor-binding domain have been shown to cross-react with SARSCoV-2 receptor-binding domain (RBD), thereby inhibiting SARS-CoV-2's entry into cells (Tai et al. 2020). A largely concordant line of reasoning has also advocated the consideration of the RBD219-N1 (a yeast-expressed potential vaccine candidate against SARS-CoV) as a heterologous vaccine against the SARS-CoV-2 (Chen et al. 2020b). These examples serve to highlight that alongside initiatives to develop novel vaccine candidates, repurposing efforts could help provide immediate solutions to address the urgent needs imposed by the ongoing pandemic situation.

A cell-based antigen delivery system against the SARS-CoV-2 has also been proposed recently using decoy cells displaying viral spike protein ( $\mathrm{Ji}$ et al. 2020). The report provides evidence from the literature to support and justify the approach, in particular, citing the example of GM-CSF expressing irradiated cells being well tolerated in clinical trials against cancer. However, no records of assays or invivo animal model studies have been provided at the moment; hence it is premature to comment on the suitability of this concept in the context of SARSCoV-2 infections.

The recent review by Iwasaki and Yang raises important caveats regarding vaccine development efforts, in particular, the phenomenon of antibodydependant enhancement (ADE). ADE occurs when therapeutically administered antibodies can exacerbate the existing pathology by enabling infection of immune cells by the invading virus, promoting inflammation, downregulation of anti-inflammatory factors like IL-10, and aberrant activation of the immune system leading up to tissue injury. The dangers associated with hyper-inflammation and immune dysregulation in the context of SARS-CoV-2 infections have been elucidated at length in Sect. 3.4. The authors outline several possible contributing factors towards ADE, including antibody specificity, choice of target epitope, affinity, subtype (IgM or $\mathrm{IgG}$ ), dosage, and patient status. Such concerns underscore the need for well-rounded vaccine development protocols and extensive preclinical 
Table 2. Vaccines being developed against COVID-19 currently in clinical trial stages

\begin{tabular}{|c|c|c|}
\hline COVID-19 vaccine developer/manufacturer & Vaccine platform & Phase \\
\hline Inovio Pharmaceuticals/ International Vaccine Institute & DNA & $1 / 2$ \\
\hline Osaka University/ AnGes/ Takara Bio & DNA & $1 / 2$ \\
\hline Cadila Healthcare Limited & DNA & $1 / 2$ \\
\hline Genexine Consortium & DNA & $1 / 2$ \\
\hline Sinovac & Inactivated & 3 \\
\hline Wuhan Institute of Biological Products/Sinopharm & Inactivated & 3 \\
\hline Beijing Institute of Biological Products/Sinopharm & Inactivated & 3 \\
\hline Institute of Medical Biology, Chinese Academy of Medical Sciences & Inactivated & $1 / 2$ \\
\hline Research Institute for Biological Safety Problems, Rep of Kazakhstan & Inactivated & $1 / 2$ \\
\hline Bharat Biotech & Inactivated & $1 / 2$ \\
\hline University of Oxford/AstraZeneca & $\begin{array}{l}\text { Non-Replicating Viral } \\
\text { Vector }\end{array}$ & 3 \\
\hline CanSino Biological Inc./Beijing Institute of Biotechnology & $\begin{array}{l}\text { Non-Replicating Viral } \\
\text { Vector }\end{array}$ & 3 \\
\hline Gamaleya Research Institute & $\begin{array}{l}\text { Non-Replicating Viral } \\
\text { Vector }\end{array}$ & 3 \\
\hline Janssen Pharmaceutical Companies & $\begin{array}{l}\text { Non-Replicating Viral } \\
\text { Vector }\end{array}$ & 3 \\
\hline ReiThera/LEUKOCARE/Univercells & $\begin{array}{l}\text { Non-Replicating Viral } \\
\text { Vector }\end{array}$ & 1 \\
\hline $\begin{array}{l}\text { Anhui Zhifei Longcom Biopharmaceutical/Institute of Microbiology, Chinese Academy } \\
\text { of Sciences }\end{array}$ & Protein Subunit & 2 \\
\hline Novavax & Protein Subunit & $1 / 2$ \\
\hline Kentucky Bioprocessing, Inc & Protein Subunit & $1 / 2$ \\
\hline Clover Biopharmaceuticals Inc./GSK/Dynavax & Protein Subunit & 1 \\
\hline Vaxine Pty Ltd/Medytox & Protein Subunit & 1 \\
\hline University of Queensland/CSL/Seqirus & Protein Subunit & 1 \\
\hline Medigen Vaccine Biologics Corporation/NIAID/Dynavax & Protein Subunit & 1 \\
\hline Instituto Finlay de Vacunas, Cuba & Protein Subunit & 1 \\
\hline FBRI SRC VB VECTOR, Rospotrebnadzor, Koltsovo & Protein Subunit & 1 \\
\hline West China Hospital, Sichuan University & Protein Subunit & 1 \\
\hline Institute Pasteur/Themis/Univ. of Pittsburg CVR/Merck Sharp \& Dohme & Replicating Viral Vector & 1 \\
\hline Moderna/NIAID & RNA & 3 \\
\hline BioNTech/Fosun Pharma/Pfizer & RNA & 3 \\
\hline Curevac & RNA & 2 \\
\hline Arcturus/Duke-NUS & RNA & $1 / 2$ \\
\hline Imperial College London & RNA & 1 \\
\hline People's Liberation Army (PLA) Academy of Military Sciences/Walvax Biotech. & RNA & 1 \\
\hline Medicago Inc. & VLP & 1 \\
\hline
\end{tabular}

evaluations in order to optimize the choice of adjuvants, mode of administration, and other relevant parameters as enlisted above. A more thorough elaboration may be found in the publication referenced (Iwasaki and Yang 2020).

The World Health Organization (WHO) is currently maintaining publicly accessible, comprehensive, and authoritative databases (https://www.who.int/publica tions/m/item/draft-landscape-of-covid-19-candidatevaccines) listing all the vaccines under clinical or preclinical evaluation (WHO 2020a). At the time of writing, 33 vaccine candidates are under clinical trial, which have been summarized in table 2. Additionally, the WHO's COVID-19 modeling ad hoc expert working group (https://www.who.int/publications/m/ item/covid-19-animal-models-summary-of-progressmade-by-the-who-covid-19-modelling-(march-04-june2020)) has also reported (based on the available results from studies across the world) that Rhesus macaques and ferrets appear to be the most suitable large animal models for studying SARS-CoV-2 infections to date (WHO 2020). Such public information initiatives are of immense benefit to encourage collaboration, avoid unnecessary and wasteful duplication of effort, and disseminate valuable data rapidly across the research community. We would also like to direct the interested 
reader to refer to an excellent summary of the SARSCoV-2 vaccine landscape by Nature Reviews Drug Discovery and authors affiliated with the Coalition for Epidemic Preparedness Innovations (CEPI) (Le et al. 2020).

\section{Conclusion}

As the current progress of the SARS-CoV-2 outbreak has made obvious, clinical management of these infections has been under multiple pressures ranging from high false-negative rates of diagnosis, contentious results on the efficacy of proposed drugs, and the threat of severely detrimental symptoms like ARDS and cytokine storm responses. The development of accessible point-of-care diagnostic devices tailor-made for low-resource settings continues to be a pressing requirement. This may be achieved by cell lysis-free workflows, increasingly sensitive and robust bioassays, improved sample collection and processing methods which minimize risks to healthcare workers, and readyto-use kits not requiring technical expertise, among other possible innovations. In this regard, RT-LAMP and CRISPR/Cas-based methods like SHERLOCK and DETECTR are notable advancements that could be explored as promising alternatives. With regard to portable diagnostic devices, few technologies hold as much promise as paper-based microfluidics. The applicability of this has already been demonstrated in the context of the Ebola and Zika outbreaks (Kaarj et al. 2018; Magro et al. 2017). While a comprehensive overview of the microfluidics domain is beyond the scope of this work, considering the immense potential of this technology we would like to direct the interested reader to refer to a dedicated review of paper-based microfluidic platforms for nucleic acid detection (Kaur and Toley 2018).

Advocating accelerated vaccine development efforts might prove to be a risky gamble, on account of the associated safety caveats which have been underscored in the preceding sections. Instead, an emphasis on designing and adopting reliable biophysical assays for comprehensive, yet rapid preclinical evaluation may be beneficial in reducing the historically high attrition rate among candidates under clinical trials. This holds especially true for studies proposing novel therapeutic agents as well, for which emerging techniques like the CETSA (cellular thermal shift assay) may help deter the occurrence of misleading false positives (Martinez Molina et al. 2013). Furthermore, as regards the application of $\mathrm{AI} / \mathrm{ML}-$ based platforms in biomedical research and diagnostics, a confluence of cross-domain expertise is crucial to ensure the development of reliable models and workflows which faithfully capture real-world dynamics. As instances of governments and healthcare agencies employing AIbased containment and prevention strategies increase, it is important that critical studies be undertaken to ascertain the true benefits and outcomes of such technological integration, rather than a reliance on anecdotal evidence alone.

Throughout our discussion, certain points have been recurrent - the advantages of leveraging existing knowledge on closely related species like the SARS $\mathrm{CoV}$, the potent efficacy of seemingly disparate techniques when applied in tandem, and the importance of collaborative efforts coupled with rapid, timely dissemination of results which may inform ongoing efforts. Requirements key to enabling these include the availability of genomic sequences, structural data, and expertly curated databases. The push towards developing modular assay workflows (with elements of automation involved) may well be a defining paradigm of future responses to such scenarios. The advent of in silico epitope screening, algorithmic vaccine and inhibitor design, and preliminary evaluation of drug libraries by molecular docking has the potential to greatly facilitate wet-labbased and clinical investigations while expediting results. However, we reiterate our concerns over adequate quality testing and rigorous experimental validation before adopting such approaches as an established norm. Skepticism must also be extended in light of a growing tendency to extrapolate trends observed from in vitro setups and unsuitable animal models to recommend clinical guidelines. We conclude our narrative on the hopeful note that the topical coverage should have appealed to both experts in virology and biomedical engineers, as well as recent entrants in these research domains. The purpose of this effort would be best served if the diverse studies described herein motivate and help lay the foundation for ambitious multidisciplinary undertakings aimed at the advancement of public health.

\section{Acknowledgements}

The authors thank Hitaishi Desai for helping with illustrations and designs for the figure panels, and Dr. Ankit Kumar Sahu and Minita Desai for proofreading and editing of the final draft. AC thanks India Alliance, 
IISER Bhopal and DBT for supporting various research programs in the lab.

\section{References}

Agrawal S, Goel AD and Gupta N 2020 Emerging prophylaxis strategies against COVID-19. Monaldi Arch. Chest Dis. https://doi.org/10.4081/monaldi.2020.1289

Ahmed SF, Quadeer AA and McKay MR 2020 Preliminary Identification of Potential Vaccine Targets for the COVID-19 Coronavirus (SARS-CoV-2) Based on SARS-CoV Immunological Studies. Viruses 12254

Apostolopoulos ID and Bessiana T 2020 Covid-19: Automatic detection from X-Ray images utilizing Transfer Learning with Convolutional Neural Networks. Phys. Eng. Sci. Med. https://doi.org/10.1007/s13246-020-00865-4

Baglivo M, Baronio M, Natalini G, Beccari T, Chiurazzi P et al. 2020 Natural small molecules as inhibitors of coronavirus lipid-dependent attachment to host cells: a possible strategy for reducing SARS-COV-2 infectivity? Acta Biomed. 91 161-164

Baruah V and Bose S 2020 Immunoinformatics-aided identification of $\mathrm{T}$ cell and $\mathrm{B}$ cell epitopes in the surface glycoprotein of 2019-nCoV. J. Med. Virol. 92 495-500

Becherer L, Borst N, Bakheit M, Frischmann S, Zengerle R et al. 2020 Loop-mediated isothermal amplification (LAMP) - review and classification of methods for sequence-specific detection. Anal. Methods 12 717-746

Beltrán-Pavez C, Márquez CL, Muñoz G, Valiente-Echeverría F, Gaggero A et al. 2020 SARS-CoV-2 detection from nasopharyngeal swab samples without RNA extraction. bioRxiv https://doi.org/10.1101/2020.03.28.013508

Bernheim A, Mei X, Huang M, Yang Y, Fayad ZA et al. 2020 Chest CT Findings in Coronavirus Disease-19 (COVID-19): Relationship to Duration of Infection. Radiology https://doi.org/10.1148/radiol.2020200463

Biran N, Ip A, Ahn J, Go RC, Wang S et al. 2020 Tocilizumab among patients with COVID-19 in the intensive care unit: a multicentre observational study. Lancet Rheumatol. https://doi.org/10.1016/S26659913(20)30277-0

Bogoch II, Watts A, Thomas-Bachli A, Huber C, Kraemer MUG et al. 2020 Pneumonia of unknown aetiology in Wuhan, China: potential for international spread via commercial air travel. J. Travel Med. 27 taaa008

Borba MGS, Val FdA, Sampaio VS, Alexandre MA et al. 2020 Chloroquine diphosphate in two different dosages as adjunctive therapy of hospitalized patients with severe respiratory syndrome in the context of coronavirus (SARS-CoV-2) infection: Preliminary safety results of a randomized, double-blinded, phase IIb clinical trial (CloroCovid-19 Study). medRxiv https://doi.org/10.1101/ 2020.04.07.20056424
Broughton JP, Deng X, Yu G, Fasching CL, Servellita V et al. 2020 CRISPR-Cas12-based detection of SARSCoV-2. Nat. Biotechnol. https://doi.org/10.1038/s41587020-0513-4

Caly L, Druce JD, Catton MG, Jans DA and Wagstaff KM 2020 The FDA-approved drug ivermectin inhibits the replication of SARS-CoV-2 in vitro. Antiviral Res. 178 104787

Cantini F, Niccoli L, Matarrese D, Nicastri E, Stobbione P et al. 2020 Baricitinib therapy in COVID-19: A pilot study on safety and clinical impact. J. Infect. 81 318-356

Cao B, Wang Y, Wen D, Liu W, Wang J et al. 2020 A Trial of Lopinavir-Ritonavir in Adults Hospitalized with Severe Covid-19. N. Engl. J. Med. 382 1787-1799

Cao Y, Liu X, Xiong L and Cai K 2020 Imaging and clinical features of patients with 2019 novel coronavirus SARSCoV-2: A systematic review and meta-analysis. J. Med. Virol. https://doi.org/10.1002/jmv.25822

Chan JF-W, Yip CC-Y, To KK-W, Tang TH-C, Wong SC-Y et al. 2020 Improved molecular diagnosis of COVID-19 by the novel, highly sensitive and specific COVID-19$\mathrm{RdRp} / \mathrm{Hel}$ real-time reverse transcription-polymerase chain reaction assay validated in vitro and with clinical specimens. J. Clin. Microbiol. https://doi.org/10.1128/ JCM.00310-20

Chen L, Xiong J, Bao L and Shi Y 2020 Convalescent plasma as a potential therapy for COVID-19. Lancet Infect. Dis. 20 398-400

Chen W-H, Hotez PJ and Bottazzi ME 2020 Potential for developing a SARS-CoV receptor-binding domain (RBD) recombinant protein as a heterologous human vaccine against coronavirus infectious disease (COVID)-19. Hum. Vaccin. Immunother. 0 1-4

Chen Z, Hu J, Zhang Z, Jiang S, Han S et al. 2020 Efficacy of hydroxychloroquine in patients with COVID-19: results of a randomized clinical trial. medRxiv https:// doi.org/10.1101/2020.03.22.20040758

Cheng C, Xiaorong Z, Zhenyu J and Weifeng H 2020 Advances in the research of cytokine storm mechanism induced by Corona Virus Disease 2019 and the corresponding immunotherapies. Zhonghua Shao Shang Za Zhi 36 E005

Chu DKW, Pan Y, Cheng SMS, Hui KPY, Krishnan P et al. 2020 Molecular Diagnosis of a Novel Coronavirus (2019nCoV) Causing an Outbreak of Pneumonia. Clin. Chem. 66 549-555

Corman VM, Landt O, Kaiser M, Molenkamp R, Meijer A et al. 2020 Detection of 2019 novel coronavirus (2019$\mathrm{nCoV}$ ) by real-time RT-PCR. Euro. Surveill. https://doi. org/10.2807/1560-7917.ES.2020.25.3.2000045

Cumhur Cure M, Kucuk A and Cure E 2020 Colchicine may not be effective in COVID-19 infection; it may even be harmful? Clin. Rheumatol. https://doi.org/10.1007/ s10067-020-05144-x 
Dai H, Zhang X, Xia J, Zhang T, Shang Y et al. 2020 Highresolution Chest $\mathrm{CT}$ Features and Clinical Characteristics of Patients Infected with COVID-19 in Jiangsu, China. Int. J. Infect. Dis. https://doi.org/10.1016/j.ijid.2020.04. 003

Dalili N 2020 Effects of Standard Protocol Therapy With or Without Colchicine in Covid-19 Infection: A Randomized Double Blind Clinical Trial. https://clinicaltrials.gov/ct2/ show/NCT04360980

Devaux CA, Rolain J-M, Colson P and Raoult D 2020 New insights on the antiviral effects of chloroquine against coronavirus: what to expect for COVID-19? Int. J. Antimicrob. Agents. https://doi.org/10.1016/j.ijantimicag. 2020.105938

Duan K, Liu B, Li C, Zhang H, Yu T et al. 2020 Effectiveness of convalescent plasma therapy in severe COVID-19 patients. Proc. Natl. Acad. Sci. U S A. https:// doi.org/10.1073/pnas.2004168117

El-Tholoth M, Bau HH and Song J 2020 A Single and TwoStage, Closed-Tube, Molecular Test for the 2019 Novel Coronavirus (COVID-19) at Home, Clinic, and Points of Entry. ChemRxiv https://doi.org/10.26434/chemrxiv. 11860137.v1

Enayatkhani M, Hasaniazad M, Faezi S, Guklani H, Davoodian $\mathrm{P}$ et al. 2020 Reverse vaccinology approach to design a novel multi-epitope vaccine candidate against COVID-19: an in silico study. J. Biomol. Struct. Dyn. https://doi.org/10.1080/07391102.2020.1756411

Fantini J, Di Scala C, Chahinian H and Yahi N 2020 Structural and molecular modelling studies reveal a new mechanism of action of chloroquine and hydroxychloroquine against SARS-CoV-2 infection. Int. J. Antimicrob. Agents. https://doi.org/10.1016/j.ijantimicag.2020. 105960

Fischer A, Sellner M, Neranjan S, Lill MA and Smieško M 2020 Inhibitors for Novel Coronavirus Protease Identified by Virtual Screening of 687 Million Compounds. ChemRxiv https://doi.org/10.26434/chemrxiv.11923239. $v 1$

Fitzpatrick F, Doherty A and Lacey G 2020 Using Artificial Intelligence in Infection Prevention. Curr. Treat. Options Infect. Dis. https://doi.org/10.1007/ s40506-020-00216-7

Furtado RHM, Berwanger O, Fonseca HA, Corrêa TD, Ferraz LR et al. 2020 Azithromycin in addition to standard of care versus standard of care alone in the treatment of patients admitted to the hospital with severe COVID-19 in Brazil (COALITION II): a randomised clinical trial. Lancet https://doi.org/10.1016/S01406736(20)31862-6

Gautret P, Lagier J-C, Parola P, Hoang VT, Meddeb L et al. 2020 Hydroxychloroquine and azithromycin as a treatment of COVID-19: results of an open-label nonrandomized clinical trial. Int. J. Antimicrob. Agents https://doi.org/10.1016/j.ijantimicag.2020.105949
Ge Y, Tian T, Huang S, Wan F, Li J et al. 2020 A data-driven drug repositioning framework discovered a potential therapeutic agent targeting COVID-19. bioRxiv https:// doi.org/10.1101/2020.03.11.986836

Glenmark 2020 Positive Ph III top-line results for favipiravir in COVID-19. https://www.thepharmaletter.com/article/ positive-ph-iii-top-line-results-for-favipiravir-in-covid-19

Grein J, Ohmagari N, Shin D, Diaz G, Asperges E et al. 2020 Compassionate Use of Remdesivir for Patients with Severe Covid-19. N. Engl. J. Med. 382 2327-2336

Guaraldi G, Meschiari M, Cozzi-Lepri A, Milic J, Tonelli R et al. 2020 Tocilizumab in patients with severe COVID19: a retrospective cohort study. Lancet Rheumatol. 2 e474-e484

Gupta D, Sahoo AK and Singh A 2020 Ivermectin: potential candidate for the treatment of Covid 19. Braz. J. Infect. Dis. 24 369-371

Halpin DMG, Singh D and Hadfield RM 2020 Inhaled corticosteroids and COVID-19: a systematic review and clinical perspective. Eur. Respir. J. https://doi.org/10. 1183/13993003.01009-2020

Hani C, Trieu NH, Saab I, Dangeard S, Bennani S et al. 2020 COVID-19 pneumonia: A review of typical CT findings and differential diagnosis. Diagn. Interv. Imaging https://doi.org/10.1016/j.diii.2020.03.014

Heidary F and Gharebaghi R 2020 Ivermectin: a systematic review from antiviral effects to COVID-19 complementary regimen. J. Antibiot. 73 593-602

Horby P, Lim WS, Emberson JR, Mafham M, Bell JL et al. 2020 Dexamethasone in Hospitalized Patients with Covid-19-Preliminary Report. N. Engl. J. Med. https:// doi.org/10.1056/NEJMoa2021436

Institute B 2020 Enabling coronavirus detection using CRISPR-Cas13: Open-access SHERLOCK research protocols and design resources. https://www.broadinstitute. org/news/enabling-coronavirus-detection-using-crisprcas13-open-access-sherlock-research-protocols-and

Irvani SSN 2020 Efficacy and Safety of Favipiravir Compared to the Base Therapeutic Regiment in Moderate to Severe COVID-19: A Randomized, Controlled, DoubleBlind, Clinical Trial. In: clinicaltrials.gov

Iwasaki A and Yang Y 2020 The potential danger of suboptimal antibody responses in COVID-19. Nat. Rev. Immuno. https://doi.org/10.1038/s41577-020-0321-6

Ji H, Yan Y, Ding B, Guo W, Brunswick M et al. 2020 Novel decoy cellular vaccine strategy utilizing transgenic antigen-expressing cells as immune presenter and adjuvant in vaccine prototype against SARS-CoV-2 virus. Med. Drug Discov. 5100026

Jin Z, Du X, Xu Y, Deng Y, Liu M et al. 2020 Structure of Mpro from COVID-19 virus and discovery of its inhibitors. Nature https://doi.org/10.1038/s41586-0202223-y

Kaarj K, Akarapipad P and Yoon J-Y 2018 Simpler, Faster, and Sensitive Zika Virus Assay Using Smartphone 
Detection of Loop-mediated Isothermal Amplification on Paper Microfluidic Chips. Sci. Rep. 812438

Kaur N and Toley BJ 2018 Paper-based nucleic acid amplification tests for point-of-care diagnostics. Analyst 143 2213-2234

Keith P, Day M, Perkins L, Moyer L, Hewitt K et al. 2020 A novel treatment approach to the novel coronavirus: an argument for the use of therapeutic plasma exchange for fulminant COVID-19. Crit. Care 24128

Khoury M, Cuenca J, Cruz FF, Figueroa FE, Rocco PRM et al. 2020 Current Status of Cell-Based Therapies for Respiratory Virus Infections: Applicability to COVID-19. Eur. Respir. J https://doi.org/10.1183/13993003.008582020

$\mathrm{Ku}$ J, Kim S, Park J, Kim T-S, Kharbash R et al. 2020 Reactive Polymer Targeting dsRNA as Universal Virus Detection Platform with Enhanced Sensitivity. Biomacromolecules https://doi.org/10.1021/acs.biomac.0c00379

Kumar S, Maurya VK, Prasad AK, Bhatt MLB and Saxena SK 2020 Structural, glycosylation and antigenic variation between 2019 novel coronavirus (2019-nCoV) and SARS coronavirus (SARS-CoV). Virusdisease 31 13-21

Le TT, Andreadakis Z, Kumar A, Román RG, Tollefsen S et al. 2020 The COVID-19 vaccine development landscape. Nat. Rev. Drug Discov. https://doi.org/10.1038/ d41573-020-00073-5

Leng Z, Zhu R, Hou W, Feng Y, Yang Y et al. 2020 Transplantation of ACE2-Mesenchymal Stem Cells Improves the Outcome of Patients with COVID-19 Pneumonia. Aging Dis. 11216

Li D, Wang D, Dong J, Wang N, Huang H et al. 2020a False-Negative Results of Real-Time Reverse-Transcriptase Polymerase Chain Reaction for Severe Acute Respiratory Syndrome Coronavirus 2: Role of DeepLearning-Based CT Diagnosis and Insights from Two Cases. Korean J. Radiol. 21 505-508

Li L, Qin L, Xu Z, Yin Y, Wang X et al. 2020b Artificial Intelligence Distinguishes COVID-19 from Community Acquired Pneumonia on Chest CT. Radiology https://doi. org/10.1148/radiol.2020200905

Li X, Wang Y, Agostinis P, Rabson A, Melino G et al. 2020c Is hydroxychloroquine beneficial for COVID-19 patients? Cell Death Dis. 11 1-6

Li Y, Li H and Zhou L 2020d EZH2-mediated H3K27me3 inhibits ACE2 expression. Biochem. Biophys. Res. Commun. https://doi.org/10.1016/j.bbrc.2020.04.010

Li Y, Yao L, Li J, Chen L, Song Y et al. 2020e Stability issues of RT-PCR testing of SARS-CoV-2 for hospitalized patients clinically diagnosed with COVID-19. J. Med. Virol. https://doi.org/10.1002/jmv.25786

Li Z, Yi Y, Luo X, Xiong N, Liu Y et al. 2020 f Development and clinical application of a rapid $\operatorname{IgM}-\operatorname{IgG}$ combined antibody test for SARS-CoV-2 infection diagnosis. $J$. Med. Virol. https://doi.org/10.1002/jmv.25727
Liu W, Liu L, Kou G, Zheng Y, Ding Y et al. 2020 Evaluation of Nucleocapsid and Spike Protein-based ELISAs for detecting antibodies against SARS-CoV-2. J. Clin. Microbiol. https://doi.org/10.1128/JCM.00461-20

Liu X and Wang X-J 2020 Potential inhibitors against 2019-nCoV coronavirus M protease from clinically approved medicines. J. Genet. Genomics. https://doi. org/10.1016/j.jgg.2020.02.001

Long C, Xu H, Shen Q, Zhang X, Fan B et al. 2020 Diagnosis of the Coronavirus disease (COVID-19): rRTPCR or CT? Eur. J. Radiol. 126108961

Long Q-X, Liu B-Z, Deng H-J, Wu G-C, Deng K et al. 2020 Antibody responses to SARS-CoV-2 in patients with COVID-19. Nat. Med. https://doi.org/10.1038/s41591020-0897-1

Lu R, Wu X, Wan Z, Li Y, Zuo L et al. 2020 Development of a Novel Reverse Transcription Loop-Mediated Isothermal Amplification Method for Rapid Detection of SARSCoV-2. Virol. Sin. https://doi.org/10.1007/s12250-02000218-1

Lucchese G 2020 Epitopes for a 2019-nCoV vaccine. Cell Mol. Immunol. https://doi.org/10.1038/s41423-020-0377$z$

Luo P, Liu Y, Qiu L, Liu X, Liu D et al. 2020 Tocilizumab treatment in COVID-19: A single center experience. $J$. Med. Viro. 92 814-818

Ma J, Xia P, Zhou Y, Liu Z, Zhou X et al. 2020 Potential effect of blood purification therapy in reducing cytokine storm as a late complication of critically ill COVID-19. Clin. Immunol. 214108408

Ma Y, Zeng H, Zhan Z, Lu H, Zeng Z et al. 2020 Corticosteroid Use in the Treatment of COVID-19: A Multicenter Retrospective Study in Hunan, China. Front. Pharmacol. 111198

Magagnoli J, Narendran S, Pereira F, Cummings T, Hardin JW et al. 2020 Outcomes of hydroxychloroquine usage in United States veterans hospitalized with Covid-19. medRxiv https://doi.org/10.1101/2020.04.16.20065920

Magro L, Jacquelin B, Escadafal C, Garneret P, Kwasiborski A et al. 2017 Paper-based RNA detection and multiplexed analysis for Ebola virus diagnostics. Sci. Rep. 71347

Mahevas M, Tran V-T, Roumier M, Chabrol A, Paule R et al. 2020 No evidence of clinical efficacy of hydroxychloroquine in patients hospitalized for COVID-19 infection with oxygen requirement: results of a study using routinely collected data to emulate a target trial. medRxiv https://doi.org/10.1101/2020.04.10.20060699

Martinez Molina D, Jafari R, Ignatushchenko M, Seki T, Larsson EA et al. 2013 Monitoring drug target engagement in cells and tissues using the cellular thermal shift assay. Science 341 84-87

Mehta P, McAuley DF, Brown M, Sanchez E, Tattersall RS et al. 2020 COVID-19: consider cytokine storm syndromes and immunosuppression. Lancet 395 1033-1034 
Metsky HC, Freije CA, Kosoko-Thoroddsen T-SF, Sabeti PC and Myhrvold C 2020 CRISPR-based COVID-19 surveillance using a genomically-comprehensive machine learning approach. bioRxiv https://doi.org/10.1101/2020. 02.26 .967026

Nalla AK, Casto AM, Huang M-LW, Perchetti GA, Sampoleo R et al. 2020 Comparative Performance of SARSCoV-2 Detection Assays using Seven Different Primer/ Probe Sets and One Assay Kit. J. Clin. Microbiol. https:// doi.org/10.1128/JCM.00557-20

Narin A, Kaya C and Pamuk Z 2020 Automatic Detection of Coronavirus Disease (COVID-19) Using X-ray Images and Deep Convolutional Neural Networks. arXiv arXiv: 2003.10849

Oldenburg CE and Doan T 2020 Azithromycin for severe COVID-19. Lancet https://doi.org/10.1016/S01406736(20)31863-8

OncoImmune I 2020 A Randomized, Double-blind, Placebocontrolled, Multi-site, Phase III Study to Evaluate the Safety and Efficacy of CD24Fc in COVID-19 Treatment. https://clinicaltrials.gov/ct2/show/NCT04317040

Ong E, Wong MU, Huffman A and He Y 2020 COVID-19 coronavirus vaccine design using reverse vaccinology and machine learning. bioRxiv https://doi.org/10.1101/2020. 03.20 .000141

Organization WH 2020a DRAFT landscape of COVID-19 candidate vaccines. WHO https://www.who.int/publications/ $\mathrm{m} /$ item/draft-landscape-of-covid-19-candidate-vaccines

Organization WH 2020b WHO discontinues hydroxychloroquine and lopinavir/ritonavir treatment arms for COVID19. Geneva, Switzerland: WHO. https://www.who.int/ news/item/04-07-2020-who-discontinues-hydroxychloro quine-and-lopinavir-ritonavir-treatment-arms-for-covid-19

Ortega JT, Serrano ML, Pujol FH and Rangel HR 2020 Unrevealing sequence and structural features of novel coronavirus using in silico approaches: The main protease as molecular target. EXCLI J. 19 400-409

Qiu T, Mao T, Wang Y, Zhou M, Qiu J et al. 2020 Identification of potential cross-protective epitope between a new type of coronavirus (2019-nCoV) and severe acute respiratory syndrome virus. J. Genet. Genomics 47 115-117

Richardson P, Griffin I, Tucker C, Smith D, Oechsle O et al. 2020 Baricitinib as potential treatment for 2019-nCoV acute respiratory disease. Lancet 395 e30-e31

Ridgeback Biotherapeutics L 2020 The Safety of EIDD2801 and Its Effect on Viral Shedding of SARS-CoV-2. https://www.clinicaltrials.gov/ct2/show/NCT04405739

Riva L, Yuan S, Yin X, Martin-Sancho L, Matsunaga N et al. 2020 A Large-scale Drug Repositioning Survey for SARS-CoV-2 Antivirals. bioRxiv https://doi.org/10.1101/ 2020.04.16.044016

Russell CD, Millar JE and Baillie JK 2020 Clinical evidence does not support corticosteroid treatment for 2019-nCoV lung injury. Lancet 395 473-475
Sanders JM, Monogue ML, Jodlowski TZ and Cutrell JB 2020 Pharmacologic Treatments for Coronavirus Disease 2019 (COVID-19): A Review. JAMA https://doi.org/10. 1001/jama.2020.6019

Sheahan TP, Sims AC, Zhou S, Graham RL, Pruijssers AJ et al. 2020 An orally bioavailable broad-spectrum antiviral inhibits SARS-CoV-2 in human airway epithelial cell cultures and multiple coronaviruses in mice. Sci. Transl. Med. 12 eabb5883

Singh AK, Majumdar S, Singh R and Misra A 2020 Role of corticosteroid in the management of COVID-19: A systemic review and a Clinician's perspective. Diabetes Metab. Syndr. 14 971-978

Stebbing J, Phelan A, Griffin I, Tucker C, Oechsle O et al. 2020 COVID-19: combining antiviral and anti-inflammatory treatments. Lancet Infect. Dis. 20 400-402

Tai W, He L, Zhang X, Pu J, Voronin D et al. 2020 Characterization of the receptor-binding domain (RBD) of 2019 novel coronavirus: implication for development of RBD protein as a viral attachment inhibitor and vaccine. Cell Mol. Immunol. https://doi.org/10.1038/s41423-0200400-4

Tian X, Li C, Huang A, Xia S, Lu S et al. 2020 Potent binding of 2019 novel coronavirus spike protein by a SARS coronavirus-specific human monoclonal antibody. Emerg. Microbes. Infect. 9 382-385

To KK-W, Tsang OT-Y, Yip CC-Y, Chan K-H, Wu T-C et al. 2020 Consistent Detection of 2019 Novel Coronavirus in Saliva. Clin. Infect. Dis. 71 841-843

Ton A-T, Gentile F, Hsing M, Ban F and Cherkasov A 2020 Rapid Identification of Potential Inhibitors of SARS-CoV2 Main Protease by Deep Docking of 1.3 Billion Compounds. ChemRxiv https://doi.org/10.26434/ chemrxiv.11860077.v1

Wang J, Hajizadeh N, Moore EE, McIntyre RC, Moore PK et al. 2020 Tissue Plasminogen Activator (tPA) Treatment for COVID-19 Associated Acute Respiratory Distress Syndrome (ARDS): A Case Series. J. Thromb. Haemost. https://doi.org/10.1111/jth.14828

Wang M, Cao R, Zhang L, Yang X, Liu J et al. 2020 Remdesivir and chloroquine effectively inhibit the recently emerged novel coronavirus (2019-nCoV) in vitro. Cell Res. 30 269-271

WHO 2020 WHO R\&D Blueprint COVID-19 Animal Models. https://www.who.int/publications/m/item/ covid-19-animal-models-summary-of-progress-madeby-the-who-covid-19-modelling-(march-04-june-2020)

Xia S, Liu M, Wang C, Xu W, Lan Q et al. 2020a Inhibition of SARS-CoV-2 (previously 2019-nCoV) infection by a highly potent pan-coronavirus fusion inhibitor targeting its spike protein that harbors a high capacity to mediate membrane fusion. Cell Res. 30 343-355

Xia S, Zhu Y, Liu M, Lan Q, Xu W et al. 2020b Fusion mechanism of 2019-nCoV and fusion inhibitors targeting 
HR1 domain in spike protein. Cell Mol. Immunol. https:// doi.org/10.1038/s41423-020-0374-2

Xiang J, Yan M, Li H, Liu T, Lin C et al. 2020 Evaluation of Enzyme-Linked Immunoassay and Colloidal GoldImmunochromatographic Assay Kit for Detection of Novel Coronavirus (SARS-Cov-2) Causing an Outbreak of Pneumonia (COVID-19). medRxiv https://doi.org/10. 1101/2020.02.27.20028787

Yan C, Cui J, Huang L, Du B, Chen L et al. 2020 Rapid and visual detection of 2019 novel coronavirus (SARS-CoV2) by a reverse transcription loop-mediated isothermal amplification assay. Clin. Microbiol. Infect. https://doi. org/10.1016/j.cmi.2020.04.001

Yang Y, Shen C, Li J, Yuan J, Yang M et al. 2020 Exuberant elevation of IP-10, MCP-3 and IL-1ra during SARS-CoV2 infection is associated with disease severity and fatal outcome. medRxiv https://doi.org/10.1101/2020.03.02. 20029975

Yang Z, Liu J, Zhou Y, Zhao X, Zhao Q et al. 2020 The effect of corticosteroid treatment on patients with coronavirus infection: a systematic review and meta-analysis. J. Infect. 81 e13-e20

Ye Z, Wang Y, Colunga-Lozano LE, Prasad M, Tangamornsuksan W et al. 2020 Efficacy and safety of corticosteroids in COVID-19 based on evidence for COVID-19, other coronavirus infections, influenza, community-acquired pneumonia and acute respiratory distress syndrome: a systematic review and meta-analysis. CMAJ 192 E756-E767

Zha L, Li S, Pan L, Tefsen B, Li Y et al. 2020 Corticosteroid treatment of patients with coronavirus disease 2019 (COVID-19). Med. J. Aust. 10.5694/mja2.50577

Zhang B, Liu S, Tan T, Huang W, Dong Y et al. 2020 Treatment With Convalescent Plasma for Critically Ill Patients With SARS-CoV-2 Infection. CHEST https://doi. org/10.1016/j.chest.2020.03.039

Zhang C, Wu Z, Li J-W, Zhao H and Wang G-Q 2020 The cytokine release syndrome (CRS) of severe COVID-19 and Interleukin-6 receptor (IL-6R) antagonist Tocilizumab may be the key to reduce the mortality. Int. J. Antimicrob. Agents https://doi.org/10.1016/j. ijantimicag.2020.105954

Zhang R, Wang X, Ni L, Di X, Ma B et al. 2020 COVID-19: Melatonin as a potential adjuvant treatment. Life Sci. $\mathbf{2 5 0}$ 117583

Zhang Y, Yu L, Tang L, Zhu M, Jin Y et al. 2020 A promising anti-cytokine-storm targeted therapy for COVID-19: The artificial-liver blood-purification system. Engineering (Beijing) https://doi.org/10.1016/j.eng.2020. 03.006 